\title{
COMMUNITY-LEVEL CONSEQUENCES OF A PLANT INVASION: EFFECTS ON THREE HABITATS IN COASTAL CALIFORNIA
}

\author{
Maria E. Alvarez ${ }^{1}$ and J. Hall Cushman ${ }^{2}$ \\ Department of Biology, Sonoma State University, Rohnert Park, California 94928 USA
}

\begin{abstract}
Biological invasion by nonnative species is a global phenomenon that has the capacity to dramatically alter native communities. However, surprisingly few studies have quantified the effects of exotic plant species on the communities they invade, or have considered how these effects vary among habitat types or seasons. Here, we used both comparative and experimental field studies to investigate the influence of Cape ivy (Delairea odorata; Asteraceae), an invasive evergreen vine native to South Africa, on three habitat types in coastal regions of northern California (coastal scrub, willow riparian, and alder riparian). In the comparative study, plots invaded by Cape ivy contained $36 \%$ fewer native plant species and $37 \%$ fewer nonnative taxa, and this pattern persisted across habitat types and seasons. The richness of grass and forb species was lower in invaded plots, whereas fern and shrub richness did not vary among zones. Native species richness was significantly lower with increasing cover of Cape ivy, but this was not the case for nonnative species. In addition, invasion by Cape ivy was associated with a $31 \%$ decrease in species diversity as well as an $88 \%$ decrease in the abundance of native seedlings and a $92 \%$ decrease in nonnative seedlings compared to uninvaded areas. After $2 \mathrm{yr}$, a Cape-ivy reduction experiment yielded similar results, with a $10 \%$ increase in the richness of native species compared to control plots, and a $43 \%$ increase in the richness of nonnative taxa. Forb species richness increased significantly when Cape-ivy cover was reduced, whereas shrub richness decreased slightly and no effects were detected for ferns and grasses. We also found that Cape-ivy reduction led to a $32 \%$ increase in plant species diversity, an $86 \%$ increase in the abundance of native seedlings, and an $85 \%$ increase for nonnative seedlings. In all cases, the effects of Cape-ivy reduction were consistent across habitat types. Collectively, our results indicate that this invader has significantly changed the composition of three different habitat types, and its control should be a major priority. However, our data also indicate that Cape ivy had negative effects on the richness of both native and nonnative plant species. Such findings suggest that a consequence of removing Cape ivy from invaded areas may be to facilitate the proliferation of other nonnative species.
\end{abstract}

Key words: biological invasions; Cape ivy (Delairea odorata, Asteraceae); community-level effects; habitat-specific effects; invasive, nonnative plant species; plant life forms; seedling recruitment; South African vine.

\section{INTRODUCTION}

Biological invasions by nonnative species are a worldwide phenomenon that threaten to dramatically change communities and ecosystems (Mooney and Drake 1986, Drake et al. 1989, Vitousek et al. 1996, 1997, Williamson 1996, Luken and Thieret 1997, Mack et al. 2000). Given the current rate and spatial scale of such invasions, the costs of control, and the unfortunate reality that eradication is rarely achieved, detailed information on these human-caused additions is urgently needed so that resource managers can prioritize control activities and evaluate the success of removal efforts.

The majority of studies addressing plant invasions have focused on the characteristics of invasive species

Manuscript received 11 June 2000; revised 12 November 2001; accepted 8 January 2001.

${ }^{1}$ Present address: Golden Gate National Recreation Area, Fort Cronkhite (Building 1064), Sausalito, California 94965 USA.

${ }^{2}$ Corresponding author. E-mail: cushman@ sonoma.edu
(Noble 1989, Reichard 1997, Vila and D'Antonio 1998, Parker 2000), the process of invasion (D'Antonio 1993, Rejmanek 1996, Weber and D'Antonio 1999), the influence of disturbance on invasion success (Huenneke et al. 1990, Hobbs and Huenneke 1992, D’Antonio and Dudley 1995), and the attributes of invaded systems (Orians 1986, Crawley 1987, Richardson et al. 1994, Levine and D'Antonio 1999, Lonsdale 1999, Stohlgren et al. 1999, Levine 2000). Despite the growing understanding of the biology of invaders, and increasing efforts to restore invaded landscapes, far less attention has focused on the consequences of plant invasions for the communities they invade (McCarthy 1997, Woods 1997, Parker et al. 1999).

Invasive plant species are often assumed to alter plant species richness, diversity, and/or composition, yet only a handful of studies have quantitatively evaluated such possibilities. In a review of the literature, we found only 11 studies that assessed the effects of invaders on such community-level parameters, with 
only five of them using experimental approaches (Luken 1990, Musil 1993, Holmes and Cowling 1997, McCarthy 1997, D'Antonio et al. 1998; for comparative studies see Kelly 1981, Cross 1982, Richardson et al. 1989, Maekawa 1991, Wood 1993, De Winton and Clayton 1996). In addition, only one of these studies (Maekawa 1991) examined the effects of the same invader across multiple habitat types or geographical regions. Although specific results varied among these studies, the general pattern was for invaded communities to exhibit reduced plant species richness compared to their uninvaded counterparts. While it may be tempting to conclude that nonnative species have consistently negative effects on the communities they invade, we believe that such a conclusion is premature. In particular, this conclusion glosses over the very likely possibility that the effects of invaders on communities vary seasonally and/or across different habitat types. In addition, invaders may have markedly different effects on native and nonnative plant species, or different plant life forms. Thus, further comparative and experimental studies will be essential for developing a comprehensive understanding of how invaders affect community composition.

Here, we summarize research that addresses the effects of Cape ivy (Delairea odorata) on three coastal plant assemblages in northern California. Although this South African species has become dominant in a wide variety of habitat types in the region, there are no studies that evaluate the impacts of this extremely invasive plant. We conducted both comparative and experimental research to address the following questions: (1) How does Cape ivy influence species richness, diversity, and composition of the plant communities it invades, and does this vine have similar effects on native and nonnative taxa? (2) Does invasion by Cape ivy alter seedling recruitment? (3) Are the effects of Cape ivy on plant communities consistent across different habitat types and seasons? and (4) How do plant communities invaded by Cape ivy respond to its removal? Answers to these questions will contribute to our general understanding of the effects of invasive species on plant communities, and will also provide land managers with urgently needed information on the effects of a highly invasive species on divergent habitat types.

\section{Study Organisms And Sites}

Cape ivy (Delairea odorata; formerly Senecio mikanioides; Asteraceae) is a perennial evergreen vine native to the Eastern Cape and Kwazulu-Natal Provinces of South Africa, where it occurs in moist montane forests at elevations ranging from 800 to $1900 \mathrm{~m}$ (Pooley 1998, Bossard et al. 2000). In California, Cape ivy flowers in December and January but does not appear to produce viable seed (Bossard et al. 2000). Within its introduced range, individual plants grow year-round, expand vegetatively through prolific stolon production, and commonly form large patches several hectares in

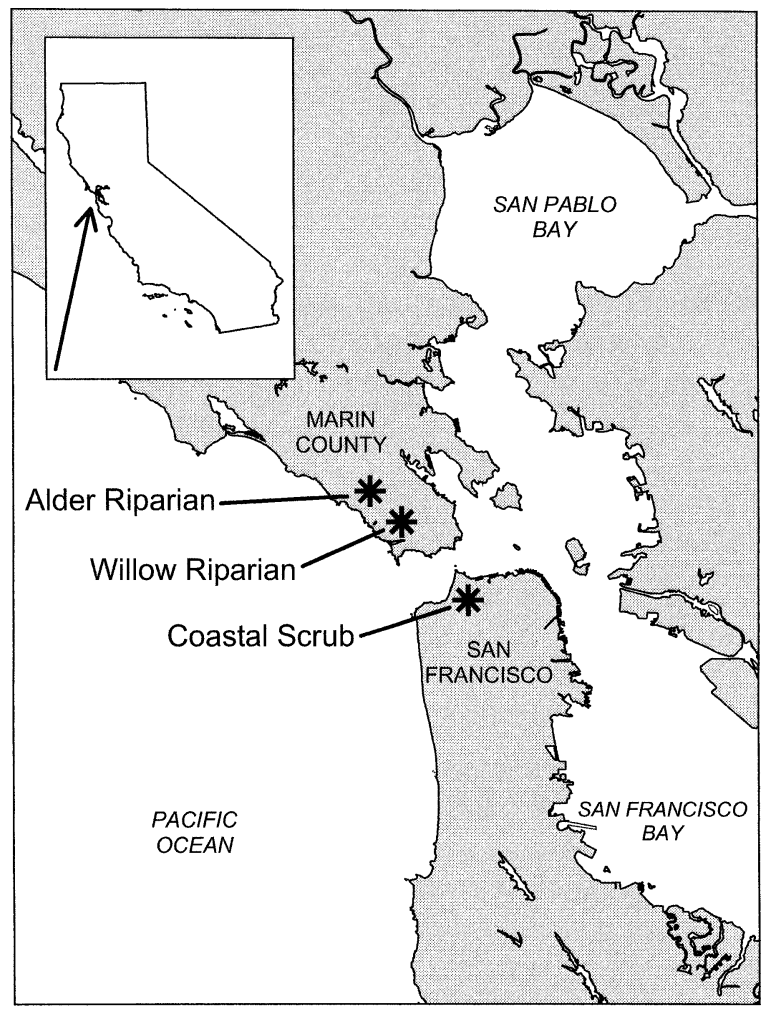

FIG. 1. Map of the San Francisco Bay area, showing the locations of three habitat types (coastal scrub, willow riparian, and alder riparian) used in this study.

size. Cape ivy can spread rapidly after invasion because it breaks apart easily and both stem nodes and leaf petioles are capable of rooting quickly (Bossard et al. 2000).

Our three study areas were located in Golden Gate National Recreation Area (GGNRA) and Mount Tamalpais State Park, within San Francisco and Marin Counties in northern California. All study areas were located within $15 \mathrm{~km}$ of each other and ranged in elevation from 4 to $95 \mathrm{~m}$ (see Fig. 1). They are characterized by mediterranean-type climate, with $90 \%$ of the annual precipitation occurring between the months of October and April. Annual precipitation for the region averages $50 \mathrm{~cm} / \mathrm{yr}$, and mean monthly temperatures range from $9^{\circ}$ to $17^{\circ} \mathrm{C}$.

The first study area (referred to as coastal scrub) is located on coastal bluffs of the Presidio in San Francisco, southwest of the Golden Gate Bridge. Vegetation at this location is characterized by coastal scrub and dominated by California blackberry (Rubus ursinus), coyote brush (Baccharis pilularis), poison oak (Toxicodendron diversilobum), lizard tail (Eriophyllum stachedifolium), California lilac (Ceanothus thrysiflorus), herbs, and grasses. Cape ivy has been present in the invaded portions of this area for no more than 5-6 yr (M. E. Alvarez, personal observation).

The second study area (referred to as willow riparian) 
TABLE 1. Results from multi-way ANOVAs for (A) comparative and (B) experimental studies evaluating the influence of Cape ivy (Delairea odorata) on 10 response variables in plots across three habitat types in northern California.

\begin{tabular}{|c|c|c|c|c|c|c|c|}
\hline \multirow[b]{2}{*}{ Source } & \multirow[b]{2}{*}{ df } & \multirow{2}{*}{$\begin{array}{c}\begin{array}{c}\text { Percent } \\
\text { cover }\end{array} \\
\text { BG or } \mathrm{CI}\end{array}$} & \multirow[b]{2}{*}{$H^{\prime}$} & \multicolumn{2}{|c|}{$\begin{array}{l}\text { Seedling } \\
\text { abundance }\end{array}$} & \multicolumn{2}{|c|}{$\begin{array}{l}\text { Plant species } \\
\text { richness }\end{array}$} \\
\hline & & & & Natives & Exotics & Natives & Exotics \\
\hline \multicolumn{8}{|l|}{ A) Comparative study } \\
\hline Invasion status (I) & 1 & $7.71 *$ & $8.09 *$ & $5.42 *$ & $21.53 * * *$ & $12.21 * *$ & $5.22 *$ \\
\hline $\mathrm{I} \times$ Habitat $(\mathrm{H})$ & 2 & 0.70 & 0.13 & 0.45 & 0.80 & 0.03 & 0.07 \\
\hline Error $(\mathrm{I} \times \mathrm{B}[\mathrm{H}])$ & 12 & & & & & & \\
\hline Habitat $(\mathrm{H})$ & 2 & 2.15 & 2.30 & 0.38 & 2.56 & 2.76 & 0.68 \\
\hline Error $(\mathrm{B}[\mathrm{H}])$ & 15 & & & & & & \\
\hline Season $(\mathrm{S})$ & 1 & $8.71 *$ & 0.04 & 4.72 & 2.16 & 2.28 & 0.81 \\
\hline $\mathrm{H} \times \mathrm{S}$ & 2 & 0.57 & 0.00 & 0.63 & 0.08 & 0.19 & $4.48 *$ \\
\hline Error $(\mathrm{S} \times \mathrm{B}[\mathrm{H}])$ & 12 & & & & & & \\
\hline Block[Habitat $](\mathrm{B}[\mathrm{H}])$ & 12 & 3.30 & 1.32 & 1.32 & 2.15 & 1.85 & 2.03 \\
\hline Error $(\mathrm{I} \times \mathrm{B}[\mathrm{H}]+\mathrm{S} \times \mathrm{B}[\mathrm{H}])-$ Resid. $)$ & 15 & & & & & & \\
\hline $\mathrm{I} \times \mathrm{S}$ & 1 & 0.57 & $5.62 *$ & 1.39 & 0.00 & $5.73 *$ & 1.40 \\
\hline $\mathrm{I} \times \mathrm{B}[\mathrm{H}]$ & 12 & 0.85 & $4.23 * *$ & 1.31 & 2.00 & $5.14 * *$ & $5.26 *$ \\
\hline $\mathrm{S} \times \mathrm{B}[\mathrm{H}]$ & 12 & 0.75 & 2.29 & 0.64 & 0.66 & 0.70 & 0.89 \\
\hline $\mathrm{I} \times \mathrm{H} \times \mathrm{S}$ & 2 & 0.78 & 1.27 & 0.15 & 0.95 & 2.58 & 0.37 \\
\hline Error (Residual) & 12 & & & & & & \\
\hline \multicolumn{8}{|l|}{ B) Experimental study } \\
\hline Cape ivy treatment (T) & 2 & $15.33 * * *$ & $12.84 * * *$ & 1.91 & $13.36 * * *$ & $4.76^{*}$ & $14.79 * * *$ \\
\hline Block[Habitat] $(\mathrm{B}[\mathrm{H}])$ & 7 & $6.26 * *$ & $4.34 * *$ & 2.38 & $3.03 *$ & $10.08 * * *$ & $2.88 *$ \\
\hline $\mathrm{T} \times \mathrm{H}$ & 4 & 0.63 & 1.43 & 0.62 & $2.98 *$ & 1.75 & 2.08 \\
\hline Error $(\mathrm{T} \times \mathrm{B}[\mathrm{H}])$ & 14 & & & & & & \\
\hline Habitat $(\mathrm{H})$ & 2 & 0.08 & 1.21 & 0.93 & 1.22 & 1.21 & 4.59 \\
\hline Error $(\mathrm{B}[\mathrm{H}])$ & 7 & & & & & & \\
\hline $\mathrm{T} \times \mathrm{B}[\mathrm{H}])$ & 14 & 1.42 & 1.88 & 0.89 & 1.57 & 0.78 & 0.92 \\
\hline Error (Residual) & 30 & & & & & & \\
\hline
\end{tabular}

Notes: Invasion status refers to the presence or absence of Cape ivy, whereas habitat corresponds to coastal scrub, willow riparian, and alder riparian. Treatment refers to Cape-ivy reduction, soil and vegetation disturbance, and no manipulation (control). BG and CI are abbreviations for bare ground and Cape ivy, respectively. $H^{\prime}$ corresponds to the Shannon diversity index. All model terms are grouped by the mean-square value used in the $F$-ratio denominator. Values shown are $F$ ratios and associated significance levels. Data on seedling abundance were log-transformed to equalize variances.

$* P<0.05 ; * * P<0.01 ; * * * P<0.001$.

is located in the Marin Headlands in Tennessee Valley. Dominant canopy vegetation consists mainly of arroyo willow (Salix lasiolepis) and some blue gum (Eucalyptus globulus) with a rich herbaceous understory. Open areas are dominated by rushes and sedges (Juncus effusus, J. phaeocephalus, and Carex obnupta), or a mix of California blackberry (Rubus ursinus), grasses, and forbs. The invasion history of study plots in this region is more variable, with Cape ivy present in several areas ranging from 4-8 yr and present in other plots for $>10 \mathrm{yr}$ (M. E. Alvarez, personal observation).

The third study area (referred to as alder riparian) is located among riparian vegetation along Redwood Creek, south of Muir Woods National Monument. The riparian canopy is comprised of red alder (Alnus rubra), willow (Salix lasiolepis), and California Bay (Umbellularia californica). The understory contains stinging nettle (Urtica holoserica), cow parsnip (Heracleum lanatum), California bee plant (Scrophularia californica), and numerous other forbs. Other woody plants are uncommon in the understory and include an occasional red elderberry (Sambucus cymosa) or twinberry (Lonicera involucrata). Cape ivy has been present in study areas of the alder riparian region for 4$10 \mathrm{yr}$ (M. E. Alvarez, personal observation).

\section{Methods}

\section{Comparison of invaded and uninvaded zones}

In 1996, we conducted a comparative study to evaluate the association between Cape-ivy invasion and plant species richness, diversity, and composition. We established five blocks within each of three habitat types (coastal scrub, willow riparian, or alder riparian). Each block contained two zones of comparable size: one invaded by Cape ivy and an adjacent zone of similar substrate and habitat characteristics that lacked Cape ivy. Within a block, we randomly subsampled the invaded and uninvaded zones in two $1.5 \times 1.5 \mathrm{~m}$ plots (four plots/block $\times$ five blocks $\times$ three habitat types $=60$ plots). All five blocks for a given habitat type were located within $1 \mathrm{~km}$ of each other and blocks averaged $15 \times 30 \mathrm{~m}$ in size.

Using three different methods, we sampled the vegetation in each of three habitat types during the spring (27 February-15 April) and summer (1 May-1 July) of 1996. To estimate species-specific percentage cover, we used point-intercept sampling methods and established four equally spaced, parallel transects $0.4 \mathrm{~m}$ apart within each of the $1.5 \times 1.5 \mathrm{~m}$ plots. Along each transect, we recorded all plant species encountered at 
TABle 1. Extended.

\begin{tabular}{|c|c|c|c|}
\hline \multicolumn{4}{|c|}{ Life-form species richness } \\
\hline Ferns & Grasses & Forbs & Shrubs \\
\hline 0.90 & $6.49 *$ & $6.80 *$ & 0.77 \\
\hline 0.30 & 1.24 & 0.11 & 0.06 \\
\hline 0.47 & $7.31 * *$ & 2.97 & $4.82 *$ \\
\hline 2.25 & 1.50 & 1.23 & $11.57 * * *$ \\
\hline 2.25 & 2.00 & $4.07 *$ & 0.00 \\
\hline 10.60 & 1.57 & 1.44 & 1.32 \\
\hline $5.44^{*}$ & 0.09 & $5.04 *$ & 0.13 \\
\hline 1.11 & $6.18 * *$ & $11.33 * * *$ & $8.00 * * *$ \\
\hline 0.44 & 0.55 & 1.67 & 0.88 \\
\hline 2.11 & 1.46 & 0.54 & 0.50 \\
\hline 0.06 & 1.36 & $21.20 * * *$ & $4.23 *$ \\
\hline $16.52 * * *$ & $11.43 * * *$ & $5.26 * *$ & 1.77 \\
\hline 0.80 & 1.63 & 2.84 & $4.22 *$ \\
\hline 0.83 & 1.91 & 0.04 & $10.48 * *$ \\
\hline $10.36 * * *$ & 1.61 & 1.22 & 0.74 \\
\hline
\end{tabular}

$25 \mathrm{~cm}$ intervals for a total of 20 points per plot. Because multiple hits at a sampling point were common, total vegetation cover often exceeded $100 \%$. To determine plant species richness in each plot, we searched the entire area of each plot and noted all plant species rooted within the plot. To quantify seedling abundance, we placed a $0.5 \times 0.5 \mathrm{~m}$ sampling quadrat in the center of each plot and recorded the identity and abundance of all seedlings. Cape ivy was included in all species richness counts.

\section{Experimental reductions of Cape ivy}

In 1996, we initiated a two-year Cape-ivy reduction experiment to more directly evaluate the influence of this invader on plant assemblages. Within each of the three habitat types, we established 30 plots distributed equally among five blocks that were invaded extensively by Cape ivy. There were six $1.5 \times 1.5 \mathrm{~m}$ plots in each of 15 blocks, which we randomly assigned to one of three treatment levels; ivy reduction, soil and vegetation disturbance, and undisturbed control (two replicates per level per block). The disturbance plots served as a control for soil and vegetation disturbance that was caused by removing Cape ivy in the reduction plots (see D'Antonio et al. 1998 for discussion of this issue). We disturbed and removed Cape ivy in manipulation plots three times during this two-year experiment: April/May 1996, June/July 1996, and June/July 1997. We removed Cape ivy from the reduction plots by carefully weeding them by hand to minimize plot disturbance. Complete removal of Cape ivy could not be achieved in these plots because the invader recolonized areas so rapidly (thus, our manipulation was best viewed as a Cape-ivy reduction rather than removal). Plots were disturbed by inserting a garden fork $8-10$ times into the soil to a depth of $5 \mathrm{~cm}$. Between 1 May and 15 July of 1998, we sampled the vegetation within all experimental plots using the same methods as described above in Methods: Comparison of invaded and uninvaded zones.

Thirty of the 90 plots were either lost during the course of our two-year field experiment (22 plots) or excluded from the analysis for statistical reasons (eight plots). Three blocks were destroyed completely (18 plots in total): one block at the coastal scrub site (fire), one at the alder riparian site (accidentally bulldozed), and one at the willow riparian site (buried with gravel during a flood). Two other blocks at the coastal scrub site were excluded from the analysis because two plots within each of them were destroyed in a landslide. After incorporating these losses, our experiment consisted of four blocks ( 24 plots) at each of the two riparian sites and two blocks (12 plots each) at the coastal scrub site.

\section{Statistical analyses}

We analyzed all data from our comparative and experimental studies using the JMP 3.1 statistical program (SAS Institute, Cary, North Carolina, USA). For the comparative study, we used four-way ANOVAs to evaluate data on percent cover of bare ground and plant species diversity $\left(H^{\prime}\right)$, with invasion status (Cape ivy present, absent), habitat type (coastal scrub, willow riparian, alder riparian), season (spring, summer), and block (1-5) nested within habitat type as the grouping factors (block was treated as a random effect). To examine the effects of these same factors on different components of the plant community, we also performed three separate MANOVAs on the following groups of response variables: (1) native and nonnative seedling abundance, (2) native and nonnative plant species richness, and (3) life-form species richness (forbs, grasses, shrubs, and ferns and their allies). For all MANOVAs with significant invasion status terms, we proceeded with "protected" ANOVAs (sensu Scheiner 1993) on each response variable. We pooled data from subsample plots within blocks for all statistical analyses in the comparative study. Prior to analysis, data on seedling abundance were log-transformed to equalize variances. We used ANCOVAs to assess the degree to which percent cover of Cape ivy per plot predicted species richness of native and nonnative plant taxa during both the spring and summer sampling periods.

For the field experiment, we used three-way ANOVAs to evaluate data on percent cover of Cape ivy and plant species diversity $\left(H^{\prime}\right)$, with Cape-ivy treatment (reduction, disturbance, and undisturbed control), habitat type, and block nested within habitat type as grouping factors (as before, block was treated as a random 


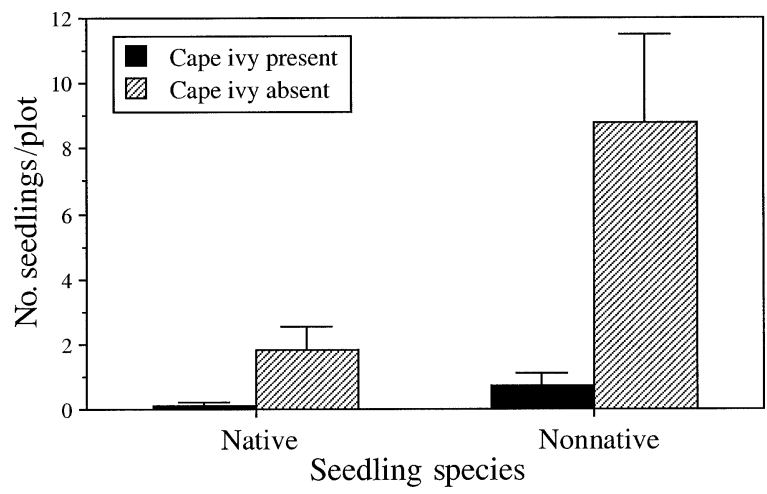

FIG. 2. Abundance (no. plant individuals per $1.5 \times 1.5$ $\mathrm{m}$ plot [mean and $1 \mathrm{SE}$ ]) of native and nonnative seedling species per plot in the presence or absence of Cape ivy (Delairea odorata).

effect). As in the comparative study, we performed separate three-way MANOVAs on native and nonnative seedling abundance, native and nonnative plant species richness, and life form species richness. We then followed up with protected ANOVAs for the individual response variables in all MANOVAs with significant treatment terms (i.e., Cape-ivy manipulation). Prior to analysis, we again log-transformed seedling abundance data to equalize variances. Because the design of this experiment was unbalanced (due to lost plots described above in Methods: Experimental reductions of Cape ivy), we used Type III sums of squares in all of our analyses.

\section{RESUlts}

\section{Comparison of invaded and uninvaded zones}

Plots invaded by Cape ivy contained on average $60 \%$ less uncolonized ground than plots lacking this vine (see the invasion status main effect for the ANOVA in Table 1A). Our data also demonstrate that invasion by Cape ivy was strongly correlated with reduced seedling recruitment, with $88 \%$ fewer native seedlings and $92 \%$ fewer nonnative seedlings in plots invaded by Cape ivy compared to uninvaded plots (Fig. 2, Tables 1A and 2B; Cape ivy seedlings were not observed in our plots at any time). The invasion status $\times$ habitat interaction term from the MANOVA was not significant for these seedling variables, indicating that the negative associations between Cape-ivy invasion and seedling abundance were consistent across the different habitat types. However, there was significant variation among blocks within habitat types for invasion status (Table 2A).

For all three habitat types, Cape-ivy invasion was correlated with a $36 \%$ reduction in the richness of native plant species and a $37 \%$ decrease in nonnative taxa (Fig. 3A, B, Tables 1A and 2A). The negative association between Cape ivy and species richness did not vary significantly among habitat types, as indicated by the nonsignificant status $\times$ habitat interaction term in the MANOVA model (Table 2A). However, we did detect significant status $\times$ season and status $\times$ block interaction terms in the MANOVA (Table 2A). Although the negative associations were apparent during both spring and summer sampling periods, there was a significant trend for invaded plots to have lower na-

TABLE 2. Results from multiway MANOVAs for (A) comparative and (B) experimental studies evaluating the influence of Cape ivy (Delairea odorata) on three different community components across three habitat types in northern California.

\begin{tabular}{|c|c|c|c|c|c|c|c|c|}
\hline \multirow[b]{3}{*}{ Variable/source } & \multicolumn{5}{|c|}{ Native and exotic plants } & & & \\
\hline & \multirow[b]{2}{*}{ df } & \multicolumn{2}{|c|}{ Seedling abundance } & \multicolumn{2}{|c|}{ Species richness } & \multicolumn{3}{|c|}{ Life form species richness } \\
\hline & & $F$ & $P$ & $F$ & $P$ & df & $F$ & $P$ \\
\hline \multicolumn{9}{|l|}{ A) Comparative study } \\
\hline Invasion status (I) & 2,11 & 21.67 & 0.0002 & 66.94 & $<0.0001$ & 4,9 & 34.19 & $<0.0001$ \\
\hline Habitat $(\mathrm{H})$ & 4,22 & 3.61 & 0.0208 & 12.16 & 0.0015 & 8,18 & 44.29 & $<0.0001$ \\
\hline Season $(\mathrm{S})$ & 2,11 & 1.86 & 0.2019 & 0.82 & 0.4649 & 4,9 & 4.79 & 0.0240 \\
\hline Block[Habitat] $(\mathrm{B}[\mathrm{H}])$ & 24,22 & 1.85 & 0.0766 & 9.70 & $<0.0001$ & 48,37 & 8.88 & $<0.0001$ \\
\hline $\mathrm{I} \times \mathrm{S}$ & 2,11 & 0.64 & 0.5463 & 5.10 & 0.0271 & 4,9 & 3.78 & 0.0451 \\
\hline $\mathrm{I} \times \mathrm{H}$ & 4,22 & 1.01 & 0.4241 & 0.25 & 0.9080 & 8,18 & 1.59 & 0.1959 \\
\hline $\mathrm{I} \times \mathrm{B}[\mathrm{H}]$ & 24,22 & 1.39 & 0.2222 & 5.06 & 0.0001 & 48,37 & 4.41 & $<0.0001$ \\
\hline $\mathrm{H} \times \mathrm{S}$ & 4,24 & 0.21 & 0.9303 & 2.08 & 0.1177 & 8,18 & 1.62 & 0.1891 \\
\hline $\mathrm{S} \times \mathrm{B}[\mathrm{H}]$ & 24,22 & 0.54 & 0.9288 & 0.86 & 0.6425 & 48. 37 & 0.78 & 0.7874 \\
\hline $\mathrm{I} \times \mathrm{H} \times \mathrm{S}$ & 4,22 & 0.50 & 0.7386 & 1.11 & 0.3751 & 8,18 & 1.20 & 0.3521 \\
\hline \multicolumn{9}{|l|}{ B) Experimental study } \\
\hline Cape ivy treatment $(\mathrm{T})$ & 4,58 & 8.10 & $<0.0001$ & 7.39 & $<0.0001$ & 8,54 & 5.93 & $<0.0001$ \\
\hline Habitat $(\mathrm{H})$ & 4,58 & 4.21 & 0.0046 & 9.94 & $<0.0001$ & 8,54 & 32.41 & $<0.0001$ \\
\hline Block[Habitat] $(\mathrm{B}[\mathrm{H}])$ & 14,58 & 2.38 & 0.0109 & 4.72 & $<0.0001$ & 28,99 & 19.36 & $<0.0001$ \\
\hline $\mathrm{T} \times \mathrm{H}$ & 8,58 & 2.60 & 0.0168 & 1.57 & 0.1529 & 16,83 & 4.08 & $<0.0001$ \\
\hline $\mathrm{T} \times \mathrm{B}[\mathrm{H}]$ & 28,58 & 0.98 & 0.5091 & 0.81 & 0.7239 & 56,107 & 2.45 & $<0.0001$ \\
\hline
\end{tabular}

Notes: All analyses used Wilks' lambda. Invasion status refers to the presence or absence of Cape ivy, whereas habitat corresponds to coastal scrub, willow riparian, and alder riparian. Treatment refers to Cape-ivy reduction, soil and vegetation disturbance, and no manipulation (control). Data on seedling abundance were log-transformed to equalize variances. 


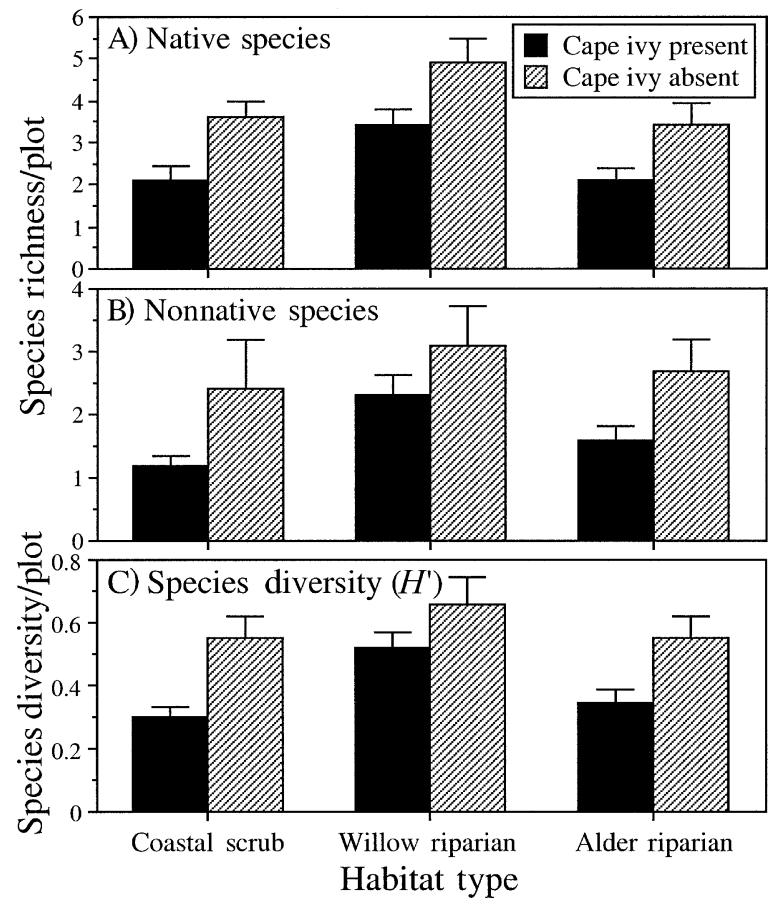

FIG. 3. (A) Native plant species richness, (B) nonnative plant species richness, and (C) plant species diversity per plot within three habitat types (coastal scrub, willow riparian, and alder riparian) in the presence or absence of Cape ivy (Delairea odorata). Data are means and $1 \mathrm{SE}$ in all cases.

tive richness in the spring than in the summer (Fig. 4, Table 1A). In addition, we detected significant spatial variation within habitat type for the association between Cape ivy and the richness of both native and nonnative species (Tables $1 \mathrm{~A}$ and $2 \mathrm{~A}$ ).

On average, plant species diversity $\left(H^{\prime}\right)$ was $31 \%$ lower in plots invaded by Cape ivy than those free of this invader (Fig. 3C, Table 1A). As with native richness, we detected significant seasonal variation in the negative association between invasion status and species diversity, with the effects of Cape ivy being great-

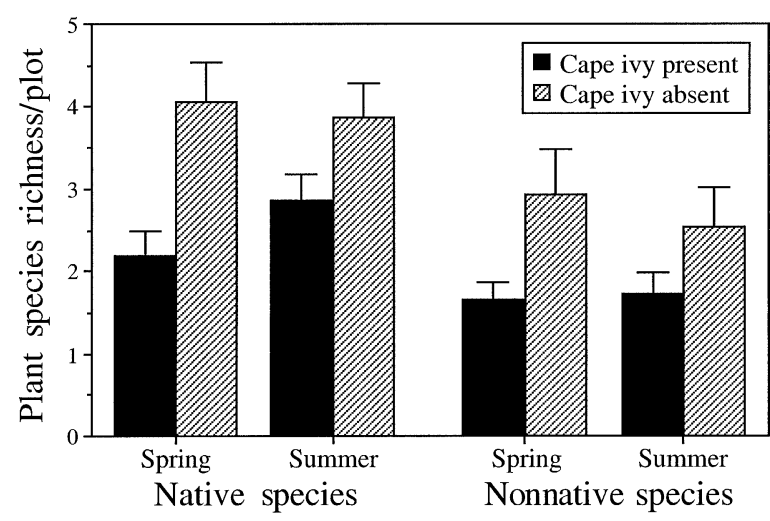

FIG. 4. Species richness (mean and $1 \mathrm{SE}$ ) of native and nonnative plants per plot during the spring and summer in the presence or absence of Cape ivy (Delairea odorata).

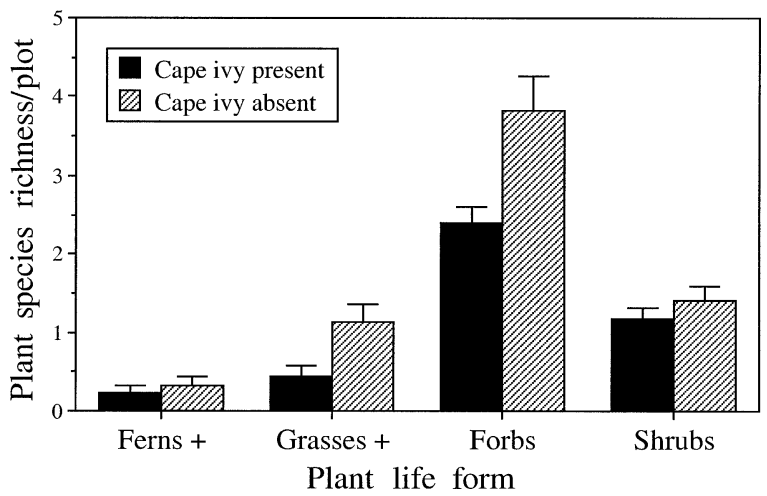

FIG. 5. Species richness (mean and $1 \mathrm{SE}$ ) of different plant life forms (ferns and their allies; grasses, sedges, and rushes; forbs; shrubs) per plot in the presence or absence of Cape ivy (Delairea odorata).

est early in the season (see the invasion status $\times$ season interaction term, Table 1A). We also detected significant spatial variation within habitat type for the association between Cape ivy and species diversity (Table 1A).

Although there was an overall negative association between species richness and invasion status for plant life forms (Table 2A), this relationship was not apparent for each group individually (Table 1A). Invaded plots had significantly fewer grass and forb species than uninvaded plots, but there was no such relationship for fern and shrub species richness (Fig. 5, Table 1A).

The number of native plant species decreased significantly as cover of Cape ivy increased within invaded plots during both the spring and summer sampling periods (Fig. 6, $F_{1,26}=32.96, P<0.0001$; spring $y=6.89-0.056 x, R^{2}=0.505$; summer $y=7.56-$ $\left.0.059 x, R^{2}=0.616\right)$. However, this relationship did not differ significantly between the two sampling periods

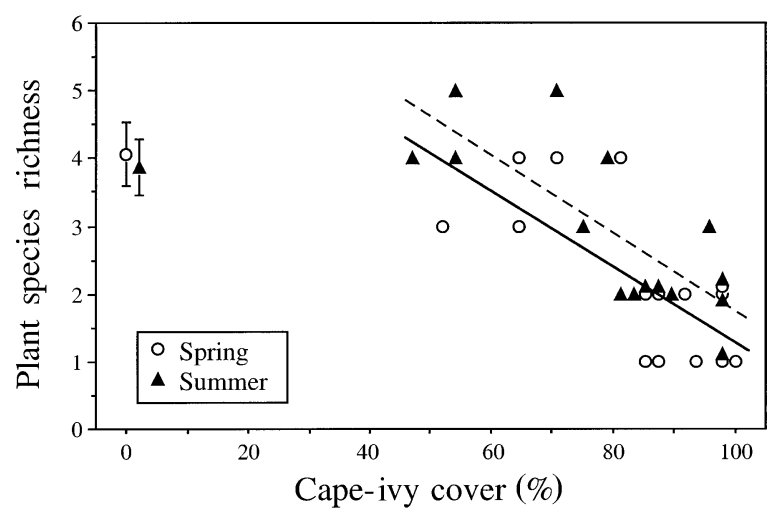

FIG. 6. Relationship between native plant species richness per plot and percent cover of Cape ivy (Delairea odorata) during spring (circles and solid line) and summer (triangles and dashed lined). Data were pooled for habitat type. Also presented (at left of data field) are data on plant species richness (mean $\pm 1 \mathrm{SE}$ ) for uninvaded plots at these two times in the growing season. 


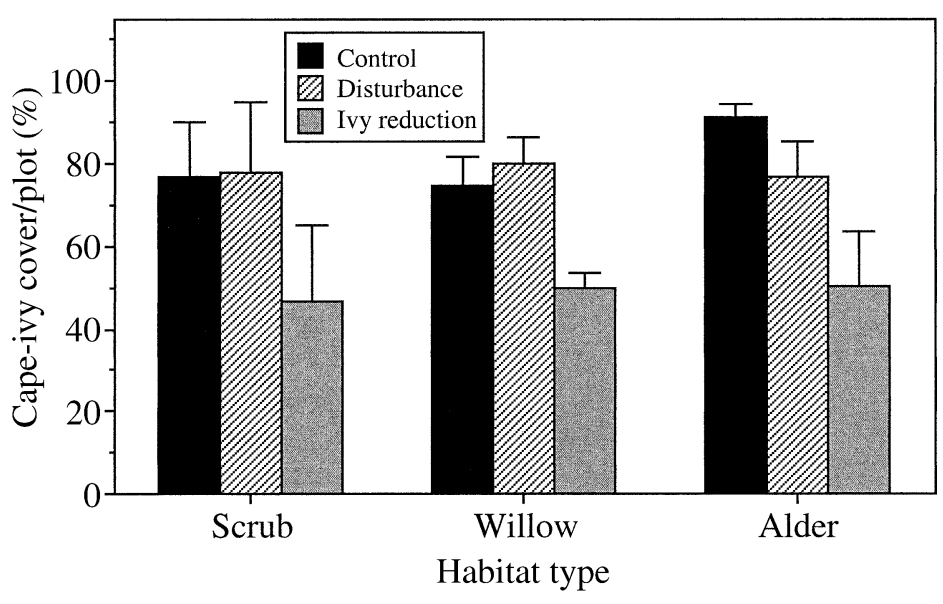

FIG. 7. Percent cover (mean and $1 \mathrm{SE}$ ) of Cape ivy (Delairea odorata) per plot within three habitat types (coastal scrub, willow riparian, and alder riparian) as a function of the three treatments: Cape-ivy reduction, soil and vegetation disturbance, and no manipulation (control). Plots were invaded heavily by Cape ivy before we initiated the experiment, and manipulated plots were treated for $2 \mathrm{yr}$.
$\left(F_{1,26}=0.02, P=0.89\right)$. In contrast, there was only a nonsignificant trend for species richness of nonnative plant taxa to decrease with increasing cover of Cape ivy $\left(F_{1,26}=3.50, P=0.073\right.$; spring $y=2.18-0.006 x$, $R^{2}=0.011$; summer $\left.y=4.29-0.032 x, R^{2}=0.308\right)$. Even though the relationship was stronger in summer than spring, slopes of the two regression lines were not significantly different $\left(F_{1,26}=1.63, P=0.21\right)$.

\section{Experimental reductions of Cape ivy}

As shown in Fig. 7, our manipulations over a twoyear period succeeded in significantly reducing cover of Cape ivy in experimental plots-from an average of $79 \%$ cover in disturbed and $82 \%$ in undisturbed control plots to $50 \%$ cover in reduction plots (Table $1 \mathrm{~b}$ ). These effects had significant consequences for seedling recruitment (Tables $1 \mathrm{~b}$ and $2 \mathrm{~b}$ ), with Cape-ivy reduction plots on average having $85 \%$ more nonnative seedlings than undisturbed control plots (Fig. 8). Reduction plots also had $86 \%$ more native seedlings than controls, although this trend was not significant. There was sig-

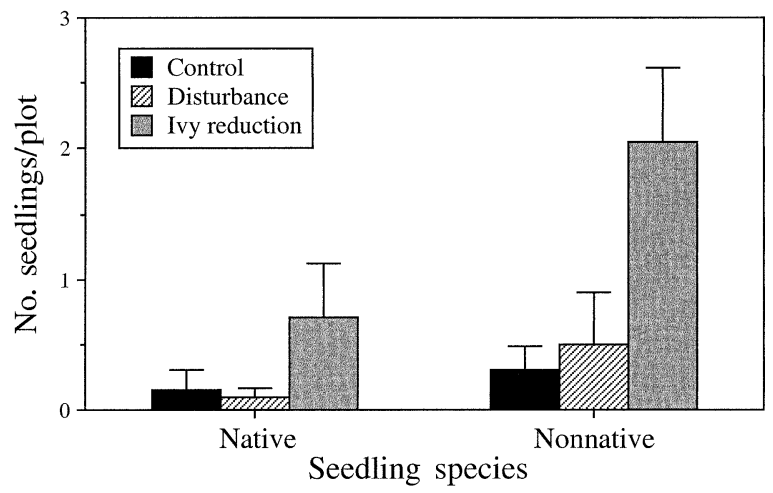

FIG. 8. Abundance (mean and $1 \mathrm{SE}$ ) of native and nonnative seedling species per plot as a function of Cape-ivy (Delairea odorata) reduction, soil and vegetation disturbance, and no manipulation (control). Plots were invaded heavily by Cape ivy before we initiated the experiment, and manipulated plots were treated for $2 \mathrm{yr}$. nificant habitat-specific variation in this relationship (Table 2b), due entirely to the absence of treatment effects for exotic seedling abundance in alder riparian habitat (Table 1b).

Our field experiment clearly demonstrated that invasion by Cape ivy had significant effects on plant species richness (Table $2 \mathrm{~b}$ ), with reduction plots containing $10 \%$ more natives species and $43 \%$ more nonnative species than undisturbed control plots (Fig. 9A, B, Table 1B). Plant species diversity was also affected significantly by our manipulations, with $H^{\prime}$ values being $32 \%$ greater in reduction plots compared to undisturbed controls and $41 \%$ greater in reduction plots compared to disturbed plots (Fig. 9C, Table 1B). There was an overall significant effect of Cape ivy manipulation on the richness of plant life forms (Table 2A), with forb species richness increasing significantly with invader reductions, whereas ferns and grasses did not (Fig. 10, Table 1B). We also detected a significant treatment effect for shrub species richness, but this was due entirely to decreased richness in reduction plots within the coastal scrub and alder riparian habitat types.

\section{DISCUSSION}

We have provided results from two concurrent studies, which collectively demonstrate that the nonnative perennial vine Cape ivy (Delairea odorata) has had significant negative effects on plant communities in northern California. In a comparative study, we found that Cape-ivy invasion was associated with reductions in the species richness and diversity $\left(H^{\prime}\right)$ of both native and nonnative species, and this pattern existed during both spring and summer sampling periods. In addition, the abundance of native and nonnative seedlings were each significantly lower in plots invaded by Cape ivy compared to uninvaded plots. Results from our field experiment strongly support these findings and demonstrate that they are due to the negative effects of Cape ivy, rather than differences between invaded and uninvaded areas. Data from both studies also indicate 


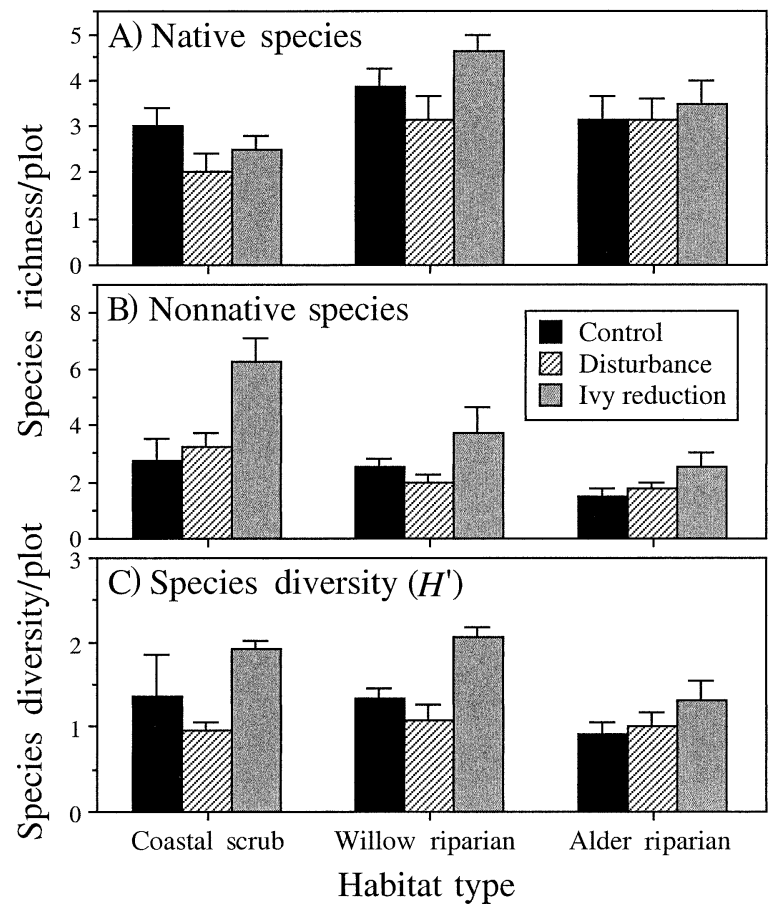

FIG. 9. (A) Native plant species richness, (B) nonnative plant species richness, and (C) plant species diversity per plot within three habitat types (coastal scrub, willow riparian, and alder riparian) as a function of Cape-ivy reduction, soil and vegetation disturbance, and no manipulation (control). Means and $1 \mathrm{SE}$ are shown in all cases. Plots were invaded heavily by Cape ivy before we initiated the experiment, and manipulated plots were treated for $2 \mathrm{yr}$.

that the negative effects of Cape ivy were consistent across three markedly different plant assemblagescoastal scrub, riparian willow, and alder riparian.

Cape ivy possesses a suite of life history characteristics that we hypothesize are responsible for its large effects on plant assemblages in different habitat types. This nonnative perennial is a stoloniferous, evergreen vine that exhibits rapid growth $(0.35-1.35 \mathrm{~m} / \mathrm{mo}$; $\mathrm{M}$. E. Alvarez, unpublished data), clonal reproduction, and pronounced tolerance of varying environmental conditions. For example, it has become established in at least 15 different habitat types in northern California and tolerates both drought and freezing temperatures (M. E. Alvarez, unpublished data). The invader's vining growth form allows it to exploit resources by growing up shrubs and trees, while its stolons travel along the soil surface, sprouting adventitious roots on contact and providing a mobile and opportunistic system that is ideal for colonizing new areas. We suspect that such traits enable Cape ivy to be highly invasive and competitively dominant (see Baker 1974, Vitousek 1986, Noble 1989, Blossy and Notzold 1995, Rejmanek 1996, Auge and Brandl 1997, Woods 1997). Presumably, this invader reduces plant species richness, diversity, and seedling abundance by monopolizing limiting resources, such as light, water, and soil nutrients. Numerous studies have found this to be the case in other systems, where nonnative plant species were competitively superior to native taxa (Swank and Douglass 1974, Caldwell et al. 1985, Eissenstat and Caldwell 1988, D’Antonio and Mahall 1991, Gordon and Rice 1993, Schierenbeck et al. 1994, Busch and Smith 1995, Huenneke 1995, Dye 1996).

The negative effects of Cape ivy on species richness were not evenly distributed among plant life forms in the community. For the comparative study, we found that species richness of grasses (along with sedges and rushes) and forbs was significantly reduced in plots invaded by Cape ivy, whereas we detected no such effects for ferns (and their allies) or shrubs (Fig. 5). Life-form data from the experimental study were not always in agreement with the comparative results (Fig. 10). As before, ferns were unaffected and the largest effects of Cape-ivy reduction were on forbs, who constituted the most abundant and species-rich life form in our study system. However, grasses were not significantly affected by our manipulations and shrub richness decreased when Cape-ivy cover was reduced in two out of three habitat types (alder riparian and coastal scrub). We hypothesize that forbs (and to a lesser extent grasses) were adversely affected by Cape ivy because they exhibit extensive resource overlap with this invader. These growth forms possess life-history characteristics that facilitate colonization (e.g., rapid growth rate, clonal reproduction, copious seed production), and enable them to capitalize on experimental reductions of Cape-ivy cover. The lack of effects for ferns may occur because they are long-lived, and the effects of Cape ivy on this group may take longer to materialize. Ferns are also strongly shade-tolerant and may be less affected by Cape ivy's smothering growth habit than other taxa. Three factors may explain the variable results for shrubs. First, shrubs are long-lived

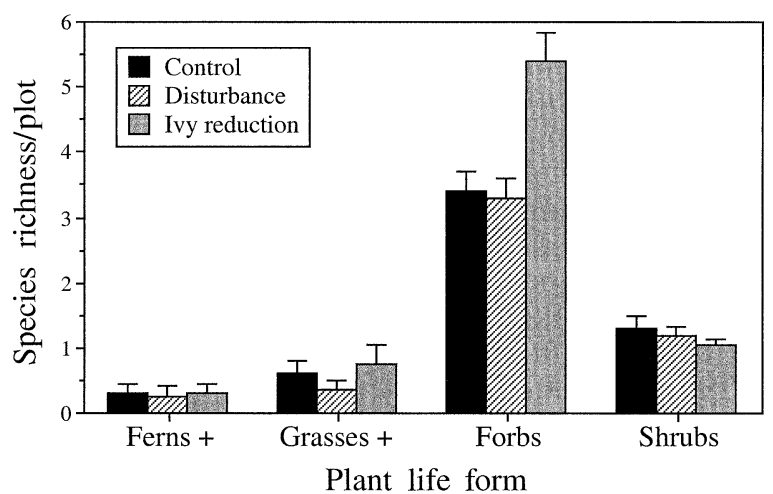

FIG. 10. Species richness (mean and $1 \mathrm{SE}$ ) of different plant life forms (ferns and their allies; grasses, sedges, and rushes; forbs; shrubs) per plot as a function of Cape-ivy reduction, soil and vegetation disturbance, and no manipulation (control). All plots were invaded heavily by Cape ivy before we initiated the experiment, and manipulated plots were treated for $2 \mathrm{yr}$. 
and probably became established prior to Cape-ivy invasion and the experimental reductions. Thus, if this vine negatively affects shrubs, the impacts should take longer to be expressed. However, a second possibility is that Cape ivy does not compete intensively with shrub taxa because the two do not overlap greatly in resource use. Shrubs have root systems that exploit water and nutrients found at much greater soil depths than those reached by Cape ivy. And third, soil and vegetation disturbances associated with Cape-ivy reductions may have adversely affected shrubs and led to decreased species richness in this group.

Our data concerning the negative relationship between Cape-ivy cover and native species richness suggest that there is a minimum level of invasion that is required before the effects of this nonnative occur. This is because mean richness for native species in uninvaded plots was considerably lower than would be predicted from the regression analysis for invaded plots (Fig. 6). We conclude that there is a negatively saturating relationship between native-plant species richness and Cape-ivy cover. However, because data on richness are lacking at low cover levels (e.g., $48 \%$ cover was the lowest level of Cape-ivy cover we observed in invaded plots), we cannot determine the specific shape of the relationship and the level of invasion when effects begin to appear.

As discussed by D'Antonio et al. (1998), field experiments that evaluate the influence of nonnative plants on the communities they invade must contend with a challenging design issue; removal of a plant invader constitutes two manipulations, invader removal and associated soil and vegetation disturbances. Thus, although this is rarely done, investigators need to control for these disturbances or else they may falsely attribute observed treatment effects to invader removal rather than associated disturbances. Anticipating that Cape-ivy removal might affect plant mortality, growth, and/or germination, we incorporated two controls into our experimental design; plots were either left unmanipulated or their soil and vegetation were disturbed to simulate Cape-ivy removal. We applied the disturbance and removal manipulations to plots three times during the experiment and are confident that our disturbances simulated the changes that occurred during the removal process. After $2 \mathrm{yr}$, our results indicate that there were no differences between disturbance and control treatment levels for most of the response variables we assessed. Only native and nonnative species richness (Fig. 9A, B) in coastal scrub habitat offered any evidence for disturbance effects, and even these cases were minimal. Further, the effects due to Cape-ivy reduction were far greater than those due to disturbance alone. Thus, in our system, the disturbance associated with removing Cape ivy was not a major confounding factor.

A striking feature of this study concerns how closely the comparative and experimental results parallel each other. In the comparative study, the combined richness of native and nonnative plant species was $36 \%$ lower in invaded plots compared to uninvaded ones. At the same time, overall richness for native and nonnative taxa increased by $26 \%$ when cover of Cape ivy was experimentally reduced in plots for $2 \mathrm{yr}$. Species diversity was also affected by similar amounts in both studies (31\% vs. 32\%), as was seedling recruitment (88-92\% vs. $85-86 \%)$. Such close agreement is important and gives added significance to our nonmanipulative results. In addition, the strong similarity may shed light on the speed with which Cape ivy alters the communities it invades, since the reduction experiment demonstrated that the invaded plant communities responded to the removal of Cape ivy relatively quickly, i.e., within $2 \mathrm{yr}$.

One of the most interesting, and potentially troubling, results presented in this study is that Cape ivy appears to have negative effects on both native and nonnative plant species. And in some cases, the effects are greater for nonnatives. The comparative study revealed that Cape-ivy invasion was associated with 88$92 \%$ reductions in the abundance of native and nonnative seedlings and $36-37 \%$ reductions in the species richness of these taxa (Figs. 2 and 3A, B). The experimental study showed that reductions in Cape-ivy cover caused an $85-86 \%$ increase in native and nonnative seedling abundance (Fig. 8). In addition, experimental reductions caused a greater increase in the richness for nonnative species (43\%) than native species (10\%; Fig. $9 \mathrm{~A}, \mathrm{~B})$. Such results suggest that removing Cape ivy from regions (or significantly reducing its cover) may facilitate the proliferation of other nonnative plant species. If this turns out to be a general finding, land managers will be faced with a challenging dilemma, one that further research may not be able to resolve: Is a system dominated by many invaders preferable to one dominated by only one? We suspect that this dilemma is not unique to our system, but will arise in any system where a dominant invader occurs in a system that already has a well-developed nonnative flora.

The research presented here provides a comprehensive evaluation of the effects that a nonnative plant species has on the multiple habitats it invades. Using both comparative and experimental approaches, we have shown that Cape ivy has significant negative effects on species richness, species diversity, and seedling abundance. Both components of this study clearly show that Cape ivy has consistently negative effects across three markedly different habitat types in northern California: coastal scrub, willow riparian, and alder riparian. Demonstrating the consistency of Cape ivy's effects in different habitats is important because nonnative species commonly invade a wide range of environments, and their impacts on plant assemblages are likely to exhibit tremendous spatial variation. If a central objective of land managers is to maintain biodiversity, then one of the first management activities 
should be to identify those invasive species that are having the greatest negative effects on composition of plant communities. Without detailed experimental studies that examine the influence of invaders and the consequences of their removal, it is difficult for land managers to determine which invaders have large effects and which resident taxa are being influenced. Such studies are crucial because they support science-based management decisions for the protection and restoration of biological diversity.

\section{ACKNOWLEDGMENTS}

We are grateful to the many volunteers who assisted with data collection, including Christine Angelo, Ingrid Cabada, Suzanne Castor, Jim Dougherty, Jennifer Drewitz, Ellen Hamingson, Sue Hubbard, Emily Raab, Dale Smith, David Trouse, and Pam Van der Leeden. We thank Nathan Rank, Caroline Christian, Kevin Hovel, and Daniel Crocker for invaluable statistical advice, David Trouse and Stephen Skartvedt for assistance with graphics, and Carla Bossard and Mona Robison for information on Cape ivy. Special thanks go to David Trouse, for his constant encouragement and enduring support throughout the project. This manuscript was improved by comments from Eric Berlow, Caroline Christian, Elizabeth Dahlhoff, Karen Gaffney, Kevin Hovel, Darca Morgan, Sean McNeil, Nathan Rank, Vanessa Rashbrook, David Richardson, Erin Siska, Jeanie Slagter, Trisha Tierney, and two anonymous reviewers. Our research was supported by funds from the National Park Service, Sonoma State University, and the National Science Foundation (DEB-9981663 to J. H. Cushman).

\section{Literature Cited}

Auge, H., and R. Brandl. 1997. Seedling recruitment in the invasive clonal shrub, Mahonia aquifolium Pursh (Nutt.). Oecologia 110:205-211.

Baker, H. G. 1974. The evolution of weeds. Annual Review of Ecology and Systematics 5:1-24.

Bossard, C. C., J. M. Randall, and M. C. Hoshovsky. 2000. Invasive plants of California's wildlands. University of California Press, Berkeley, California, USA.

Busch, D. E., and S. D. Smith. 1995. Mechanisms associated with decline of woody species in riparian ecosystems of the southwestern United States. Ecological Monographs 65: 347-370.

Caldwell, M. M., D. Eissenstat, and J. H. Richards. 1985. Competition for phosphorous: differential uptake from dual isotope-labeled soil interspaces between shrub and grass. Science 229:384-386.

Crawley, M. J. 1987. What makes a community invasible? Pages 429-453 in A. J. Gray, M. J. Crawley, and P. J. Edwards, editors. Colonizers, succession and stability. Blackwell Scientific Publications, Oxford, UK.

Cross, J. R. 1982. The invasion and impact of Rhododendron ponticum in native Irish vegetation. Journal of Life Science Royal Dublin Society 3:209-220.

D’Antonio, C. M. 1993. Mechanisms controlling invasion of coastal plant communities by the alien succulent Carpobrotus edulis. Ecology 74:83-95.

D'Antonio, C. M., and T. L. Dudley. 1995. Biological invasions as agents of change on islands versus mainlands. Pages 103-121 in P. M. Vitousek, H. Adsersen, and L. L. Loope, editors. Islands: biological diversity and ecosystem function. Springer-Verlag, Berlin, Germany.

D’Antonio, C. M., F. R. Hughes, M. Mack, D. Hitchcock, and P. M. Vitousek. 1998. The response of native species to removal of invasive exotic grasses in a seasonally dry Hawaiian woodland. Journal of Vegetation Science 9:699712.
D'Antonio, C. M., and B. E. Mahall. 1991. Root profiles and competition between the invasive, exotic perennial, Carpobrotus edulis, and two native shrub species in California coastal scrub. American Journal of Botany 78:885-894.

De Winton, M. D., and J. S. Clayton. 1996. The impact of invasive submerged weed species on seed banks in lake sediments. Aquatic Botany 53:31-45.

Drake, J. A., H. A. Mooney, F. di Castri, R. H. Groves, F. J. Kruger, M. Rejmanek, and M. Williamson. 1989. Biological invasions: a global perspective. John Wiley and Sons, New York, New York, USA.

Dye, P. 1996. Climate, forest and streamflow relationships in South African forested catchments. Commonwealth Forestry Review 75:31-38.

Eissenstat, D. M., and M. M. Caldwell. 1988. Competitive ability is linked to rates of water extraction (a field study between two aridland tussock grasses). Oecologia 75:1-7.

Gordon, D., and K. J. Rice. 1993. Competitive effects of annual grasses on soil and water and blue oak seedlings. Ecology 74:68-82.

Hobbs, R. J., and L. F. Huenneke. 1992. Disturbance, diversity, and invasion: implications for conservation. Conservation Biology 6:324-337.

Holmes, P. M., and R. M. Cowling. 1997. The effects of invasive Acacia saligna on the guild structure and regeneration capabilities of South African fynbos shrublands. Journal of Applied Ecology 34:317-332.

Huenneke, L. F. 1995. Potential interference between a threatened endemic thistle and an invasive nonnative thistle. Conservation Biology 9:416-425.

Huenneke, L. F., S. P. Hamburg, R. Koide, H. A. Mooney, and P. M. Vitousek. 1990. Effects of soil resources on plant invasion and community structure in Californian serpentine grassland. Ecology 71:478-491.

Kelly, D. L. 1981. The native forest vegetation of Killarney, south-west Ireland: an ecological account. Journal of Ecology 69:437-472.

Levine, J. M. 2000. Species diversity and biological invasions: relating local process to community pattern. Science 288:852-854.

Levine, J. M., and C. M. D'Antonio. 1999. Elton revisited: a review of evidence linking diversity and invasibility. Oikos 87:15-26.

Lonsdale, W. M. 1999. Global patterns of plant invasions and the concept of invasibility. Ecology 80:1522-1536.

Luken, J. O. 1990. Forest and pasture communities respond differently to cutting of exotic Amur honeysuckle (Kentucky). Restoration and Management Notes 8:122.

Luken, J. O., and J. W. Thieret, editors. 1997. Assessment and management of plant invasions. Springer-Verlag, New York, New York, USA.

Mack, R. N., D. Simberloff, W. M. Lonsdale, H. Evans, M. Clout, and F. A. Bazzaz. 2000. Biological invasions: causes, epidemiology, global consequences, and control. Ecological Applications 10:689-710.

Maekawa, M.-A. 1991. Impact of biological invasion of Robinia pseudo-acacia on zonation and species diversity of dune vegetation in central Japan. Japanese Journal of Ecology 47:131-143.

McCarthy, B. 1997. Response of a forest understory community to experimental removal. Pages $117-130$ in J. O. Luken and J. W. Thieret, editors. Assessment and management of plant invasions. Springer-Verlag, New York, New York, USA.

Mooney, H. A., and J. A. Drake. 1986. Ecology of biological invasions of North America and Hawaii. Springer-Verlag, New York, New York, USA.

Musil, C. F. 1993. Effect of invasive Australian acacias on the regeneration, growth, and nutrient chemistry of South 
African lowland fynbos. Journal of Applied Ecology 30: 361-372.

Noble, I. R. 1989. Attributes of invaders and the invading process: terrestrial and vascular plants. Pages 301-328 in J. A. Drake, H. A. Mooney, F. di Castri, R. H. Groves, F. J. Kruger, M. Rejmanek, and M. Williamson, editors. Biological invasions: a global perspective. John Wiley and Sons, New York, New York, USA.

Orians, G. H. 1986. Site characteristics favoring invasions. Pages 133-148 in H. A. Mooney and J. A. Drake, editors. Ecology of biological invasions of North America and Hawaii. Springer-Verlag, New York, New York, USA.

Parker, I. M. 2000. Invasion dynamics of Cytisus scoparius: a matrix model approach. Ecological Applications 10:726743.

Parker, I. M., D. Simberloff, W. M. Lonsdale, K. Goodell, M. Wonham, P. M. Kareiva, M. H. Williamson, B. Von Holle, P. M. Moyle, J. E. Meyers, and L. Goldwasser. 1999. Impact: toward a framework for understanding the ecological effects of invaders. Biological Invasions 1:3-19.

Pooley, E. 1998. A field guide to the wildflowers of KwazuluNatal and the Eastern Region. Natal Flora Publication Trust, Durban, South Africa.

Reichard, S. H. 1997. Predicting invasions of woody plants introduced into North America. Conservation Biology 11: 193-202.

Rejmanek, M. 1996. A theory of seed plant invasiveness: the first sketch. Biological Conservation 78:171-181.

Richardson, D. M., I. A. W. Macdonald, and G. G. Forsyth. 1989. Reductions in plant species richness under stands of alien trees and shrubs in the fynbos biome. South African Forestry Journal 149:1-8.

Richardson, D. M., P. A. Williams, and R. J. Hobbs. 1994. Pine invasions in the Southern Hemisphere: determinants of spread and invadability. Journal of Biogeography 21: 511-527.

Scheiner, S. M. 1993. MANOVA: multiple response variables and multispecies interactions. Pages 94-112 in S. M. Scheiner and J. Gurevitch, editors. Design and analysis of eco- logical experiments. Chapman and Hall, New York, New York, USA.

Schierenbeck, K. A., R. N. Mack, and R. R. Scharitz. 1994. Effects of herbivory on growth and biomass allocation in native and introduced species of Lonicera. Ecology 75: $1661-1671$.

Stohlgren, T. J., D. Binkley, G. W. Chong, M. A. Kalkhan, L. D. Schell, K. A. Bull, Y. Otsuki, G. Newman, M. Bashkin, and Y. Son. 1999. Exotic plant species invade hot spots of native plant diversity. Ecological Monographs 69:2546.

Swank, W. T., and J. E. Douglass. 1974. Streamflow greatly reduced by converting deciduous hardwood stands to pine. Science 185:857-859.

Vila, M., and C. M. D'Antonio. 1998. Fruit choice and seed dispersal of invasive vs. noninvasive Carpobrotus (Aizoaceae) in coastal California. Ecology 79:1053-1060.

Vitousek, P. M. 1986. Biological invasions and ecosystems properties: can species make a difference? Pages 163-178 in H. A. Mooney and J. A. Drake, editors. Ecology of biological invasions of North America and Hawaii. Springer-Verlag, New York, New York, USA.

Vitousek, P. M., C. M. D'Antonio, L. L. Loope, M. Rejmanek, and R. Westbrooks. 1997. Introduced species: a significant component of human-caused global change. New Zealand Journal of Ecology 21:1-16.

Vitousek, P. M., C. M. D'Antonio, L. L. Loope, and R. Westbrooks. 1996. Biological invasions as global environmental change. American Scientist 84:468-478.

Weber, E., and C. M. D'Antonio. 1999. Phenotypic plasticity in hybridizing Carpobrotus spp. (Aizoaceae) from coastal California and its role in plant invasion. Canadian Journal of Botany 77:1411-1418.

Williamson, M. 1996. Biological invasions. Chapman and Hall, London, UK.

Woods, K. D. 1997. Community response to plant invasion. Pages 56-68 in J. O. Luken and J. W. Thieret, editors. Assessment and management of plant invasions. SpringerVerlag, New York, New York, USA. 